\title{
A Reusable Capacitive Immunosensor Based on a CuS Ultrathin Film Constructed by Using a Surface Sol-Gel Technique
}

\author{
Zhan Wu, ${ }^{*} * *$ Zhong CAO, ${ }^{*}, * \dagger$ Ju-Lan Zeng, ${ }^{*}$ Ling Zhang, ${ }^{*}$ Xia ChU, ${ }^{*}{ }^{*}$ Guo-Li Shen, ${ }^{* *}$ and \\ Ru-Qin YU**
}

\author{
*Hunan Provincial Key Laboratory of Materials Protection for Electric Power and Transportation, \\ School of Chemistry and Biological Engineering, Changsha University of Science and Technology, \\ Changsha 410004, P. R. China \\ **State Key Laboratory of Chemo/Bio-Sensing and Chemometrics, College of Chemistry and \\ Chemical Engineering, Hunan University, Changsha 410082, P. R. China
}

\begin{abstract}
A capacitive sensing method based on a CuS ultrathin film modified electrode prepared by a surface sol-gel technique has been developed for the direct detection of human $\operatorname{IgA}$. The resulting CuS film was investigated with cyclic voltammetry (CV), impedance spectroscopy, and quartz crystal microbalance (QCM). CV and impedance examinations showed that the $\mathrm{CuS}$ film formed on the gold electrode surface was insulated, and was applicable to form an insulating layer of a capacitive immunosensor. With QCM measurements, the thickness of the CuS film was evaluated to be $5.8 \mathrm{~nm}$. The capacitance change was greatly increased by a $\mathrm{CuS}$ nanofilm-based immunosensor, which was initiated by the recognition of an immobilized antibody and the target antigen. The capacitance of the immunosensor corresponding to the concentration of human IgA was investigated by potentiostatic-step measurements. A linear calibration curve was obtained in the range of $1.81-90.5 \mathrm{ng} \mathrm{ml}^{-1}$ with a detection limit of $1.81 \mathrm{ng} \mathrm{ml}^{-1}$. There were no obvious interferences from the nonspecific adsorption of other proteins. With nice reproducibility and regeneration capacity, the CuS ultrathin film modified immunosensor could be used for the detection of human IgA in serum samples with a recovery of $96.1-104.4 \%$, showing its promising applicability and reliability.
\end{abstract}

(Received March 23, 2010; Accepted June 30, 2010; Published September 10, 2010)

\section{Introduction}

With high selectivity and sensitivity, immunosensors have attracted extensive attention in clinical diagnosis, food analysis and the monitoring of environment contaminants. ${ }^{1-4}$ Immunosensors can be divided into two dominating kinds: direct (label-free) and labeled. ${ }^{5}$ For a labeled immunosensor, it was expensive, time consuming and the procedure complicated. However, a label-free immunosensor ${ }^{6,7}$ has provoked more interest for many reasons, such as simplicity and real-time compared with the traditional immunoassay technology, like enzyme-linked immunosorbent assay (ELISA) ${ }^{8}$ and radioimmunoassay. ${ }^{9}$ Among those immunosensors, the capacitive immunosensor has attracted more interest with high sensitivity, rapid test time and common instrumentations ${ }^{10-15}$ compared with other types of direct biosensors, such as surface plasmon resonance, ${ }^{16,17}$ quartz crystal microbalance (QCM) ${ }^{18}$ surface acoustic wave, ${ }^{19}$ and surface scanning detection. ${ }^{20}$

The fabrication of a biocompatible layer is more pivotal to a capacitive immunosensor. It must firstly be sufficiently insulated and hole-free, or else electro-activated ions can move through the layer, causing interference of the faradaic current, leading to a decrease or disappearance of the signal. Furthermore, it should be extraordinary thin. Otherwise, the capacitance of the

$\dagger$ To whom correspondence should be addressed.

E-mail: zhongcao04@yahoo.com.cn diffuse layer of the electrode might utmost contribute to the total capacitance of the immunosensor, which would induce a capacitance decrease, caused by the interaction of an antibody-antigen, which could not be prominently detected..$^{21,22}$

Self-assembled monolayers (SAMs) on noble-metal surfaces were often employed in biosensor technology based on capacitance measurements. ${ }^{23,24}$ Compounds containing thiol, ${ }^{25}$ sulfide $^{26}$ and disulfide ${ }^{27}$ groups were often chosen to spontaneously form functional films to immobilize biomolecules. SAMs have presented highly ordered and well-organized structure on metal substrates. ${ }^{28}$ However, capacitive immunosensors based on SAMs have often adopted the covalent immobilization technology of antibodys on thiol-modified films, which had a relatively long analysis time, and made the procedure complicated. On the other hand, the self-assembled layer might not be able to completely cover the gold electrode surface to keep the surface of the resulting electrode in sufficient electric isolation. So, to block any possible pinholes or defects on the surface, the electrode should be assembled once again with one kind of long-chain alkanethiol solution, such as $n$-dodecanethiol. ${ }^{22}$ However, such a treatment might cause a loss of activity and sensitivity of the capacitance immunosensor. Recently, Jiang et al. reported a capacitive immumosensor based on an antibody-embedded ultrathin $\gamma$-alumina sol-gel film for the direct determination of liver fibrosis markers. ${ }^{12}$ Compared with the SAMs technique, the ultrathin alumina sol-gel film possessed good biocompatibility with a low detection limit. However, this style of biosensor with an 


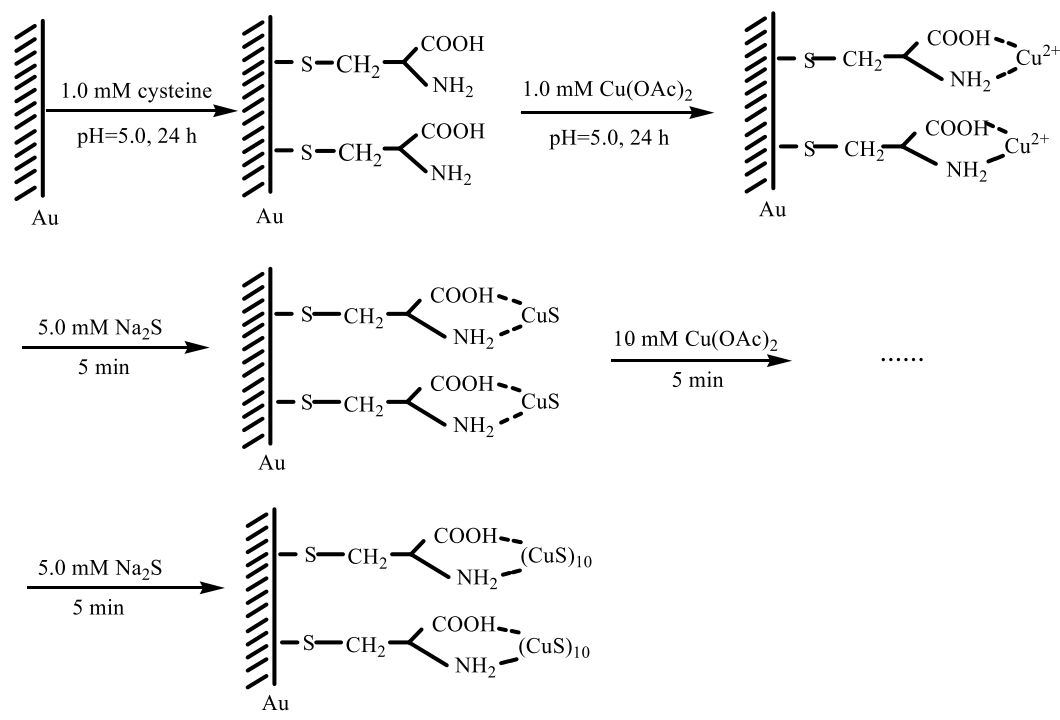

Fig. 1 Schematic illustration of the process for $\mathrm{CuS}$ ultrathin film fabrication.

antibody-embedded gel film was not able to regenerate well, and a new electrode had to be prepared for each measurement.

In this paper, a novel method for preparing capacitive immunosensors based on $\mathrm{CuS}$ sol-gel film is presented. A potentiostatic-step method was employed to measure the capacitance change for bio-analysis purposes by its high sensitivity, rapid test time and simplicity. The fabricated $\mathrm{CuS}$ film was an insulative and ultrathin layer (about $6 \mathrm{~nm}$ ) with the thickness being controllable, thus allowing a label-free capacitive measuring approach for many times of use-regeneration. The interaction principal of a $\mathrm{CuS}$ gel film modified capacitance immunosensor is that the copper ions could form a chelate with $-\mathrm{NH}_{2}$ and $-\mathrm{COOH}$ groups, making it possible to examine various protein biomolecules, like human immunoglobulin A, which has demonstrated the applicability of $\mathrm{CuS}$ gel film as a capacitance immunosensor.

\section{Experimental}

\section{Reagents and apparatus}

Human immunoglobulin A (human $\operatorname{Ig} \mathrm{A}$ ) and goat anti-human IgA antibody were purchased in the lyophilized form from China Biotechnology Co., Shanghai Institute of Biological Products (Shanghai, China). Bovine serum albumin (BSA) was purchased from Beijing DingGuo Biological Company (Beijing, China). Normal human reference serum (containing $11.4 \mathrm{mg} \mathrm{ml}^{-1}$ immunoglobulin $\mathrm{G}(\mathrm{IgG})$ ) and Complement III $\left(\mathrm{C}_{3}, 9.8 \mathrm{mg} \mathrm{ml}^{-1}\right)$ were obtained from Sino-American Biotechnology Co. (Shanghai, China). Copper acetate $\mathrm{Cu}(\mathrm{OAc})_{2}$ was purchased from Yuanju Biological Technology Co. (Shanghai, China). Glycine was obtained from Sigma-Aldrich Co. (USA). Sodium sulfide was purchased from Xilong Chemical Plant (Shantou,

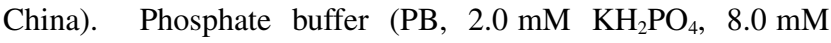
$\mathrm{Na}_{2} \mathrm{HPO}_{4}, \mathrm{pH}$ 7.0) and acetic acid buffer (HOAc-NaOAc, $0.10 \mathrm{M}, \mathrm{pH}$ 5.0) solutions were used in the experiment. Human IgA standard solutions were diluted from a stock solution $\left(1.81 \mathrm{mg} \mathrm{ml}^{-1}\right)$ with a PB solution. A goat anti-human $\operatorname{IgA}$ solution $\left(3.5 \mathrm{mg} \mathrm{ml}^{-1}\right)$ and a BSA solution $\left(1.0 \mathrm{mg} \mathrm{ml}^{-1}\right)$ were prepared by dissolving the powder with the PB solution. All other chemical reagents were of analytical reagent grade and used as received. Double-distilled water was used throughout the experiment.

Piezoelectric quartz crystals (AT-cut, $9 \mathrm{MHz}$, gold electrode $\left.\left(0.2826 \mathrm{~cm}^{2}\right)\right)$ were provided by Shanghai Chenhua Equipment (Shanghai, China). To avoid any disturbance in the electrochemical measurement, the silver wires of the crystal were sealed with insulated glue. The crystal was driven through an oscillator circuit (TTL-IC). A high-frequency counter (Model FC 1250, Wellstar) was used to record the oscillation frequency.

All electrochemical experiments were performed in a conventional electrochemical cell containing a three-electrode system in a $25-\mathrm{mL}$ batch cell. The working electrode was a gold disk electrode $(5.0 \mathrm{~mm}$ diameter $)$, the auxiliary electrode was a platinum foil and the reference electrode was a saturated calomel electrode (SCE). The temperature was kept at room temperature. All potentials measured referred to the SCE.

Potentiostatic-step measurements for immunosensors were performed with an electrochemistry working station (Model CHI-760B; $\mathrm{CH}$ Instruments, USA) in a $10 \mathrm{mM}$ PB solution ( $\mathrm{pH}$ 7.0). Cyclic voltammetric measurements were implemented with $\mathrm{CHI}-760 \mathrm{~B}$ simultaneously in the presence of a $5.0 \mathrm{mM}$ $\mathrm{K}_{3}\left[\mathrm{Fe}(\mathrm{CN})_{6}\right] / \mathrm{K}_{4}\left[\mathrm{Fe}(\mathrm{CN})_{6}\right]$ (1:1) mixture as a redox probe in a $10 \mathrm{mM} \mathrm{PB}$ solution containing $0.1 \mathrm{M} \mathrm{KCl} \mathrm{(pH} \mathrm{7.0).}$ The impedance was checked using a Multichannel Potentiostat with EC-Lab V6.70 and ZsimpWin Ver. 2.00 software (Model VMP2; EG\&G Princeton Applied Research, Princeton, NJ) in a $10 \mathrm{mM}$ PB solution ( $\mathrm{pH} 7.0)$ containing a $5.0 \mathrm{mM}$ $\mathrm{K}_{3}\left[\mathrm{Fe}(\mathrm{CN})_{6}\right] / \mathrm{K}_{4}\left[\mathrm{Fe}(\mathrm{CN})_{6}\right](1: 1)$ mixture and $0.1 \mathrm{M} \mathrm{KCl}$. A sinusoidal potential modulation of $\pm 5 \mathrm{mV}$ amplitude in the frequency range from $0.1 \mathrm{~Hz}$ to $100 \mathrm{kHz}$ was superimposed at a potential of $250 \mathrm{mV}$ ( vs. SCE).

\section{Preparation of $\mathrm{CuS}$ ultrathin film}

The fabrication process of $\mathrm{CuS}$ film is illustrated in Fig. 1. The gold electrode of the quartz crystal as substrate was firstly cleaned with a "piranha" solution containing 3 parts $(98 \%)$ of $\mathrm{H}_{2} \mathrm{SO}_{4}$ and 1 part $(30 \%)$ of $\mathrm{H}_{2} \mathrm{O}_{2}$, then rinsed with double-distilled water and dried with pure nitrogen gas (Caution: Because "Piranha" solution reacts violently with organic compounds, it should be handled with extreme care, and not be stored in a 
sealed container).

The treated electrode was immediately immersed in a solution of $1.0 \times 10^{-3} \mathrm{M}$ cysteine in a HOAc-NaOAc buffer solution (pH 5.0) for $24 \mathrm{~h}$ at $4^{\circ} \mathrm{C}$. After being taken from the solution, the electrode was rinsed with a HOAc-NaOAc buffer solution and double-distilled water, and blown dry with nitrogen gas. The electrode was then immersed in $1.0 \times 10^{-3} \mathrm{M} \mathrm{Cu}(\mathrm{OAc})_{2}$ in a HOAc-NaOAc buffer solution ( $\mathrm{pH}$ 5.0) for another $24 \mathrm{~h}$ at $4^{\circ} \mathrm{C}$, followed by procedures mentioned elsewhere. ${ }^{29,30}$ After the above-mentioned operations, the $\mathrm{Cu}^{2+}$ ion was assembled on the surface of the gold electrode.

The resulting electrode was alternately dipped in a solution of $5.0 \mathrm{mM} \mathrm{Na} \mathrm{Na}_{2} \mathrm{~S}$, prepared freshly, and a solution of $10 \mathrm{mM}$ $\mathrm{Cu}(\mathrm{OAc})_{2}$, each for $5 \mathrm{~min}$ until 10 bilayers of $\mathrm{CuS}$ were assembled on the electrode. After each immersing, the electrode was rinsed with double-distilled water and dried with $\mathrm{N}_{2}$. The film of $\mathrm{CuS}$ was then aged for $2 \mathrm{~h}$ at room temperature. For each assembly on the gold electrode, the microgravimetric characterization of the film of $\mathrm{CuS}$ could be monitored by using a quartz crystal microbalance (QCM).

\section{Measurement procedure}

Prior to use, the prepared Au electrode based on $\mathrm{CuS}$ ultrathin film was washed with double-distilled water and dried with $\mathrm{N}_{2}$. Then, the goat anti-human $\operatorname{IgA}\left(50 \mu \mathrm{l}, 3.5 \mathrm{mg} \mathrm{ml}^{-1}\right)$, BSA $\left(50 \mu \mathrm{l}, 1.0 \mathrm{mg} \mathrm{ml}^{-1}\right)$, and human $\operatorname{IgA}$ standard solution $(50 \mu \mathrm{l})$ were applied in turn on the surface of the $\mathrm{CuS}$ film, and each was allowed to react for $1 \mathrm{~h}$ at $37^{\circ} \mathrm{C}$. After each adsorption, the electrode was washed with $0.1 \mathrm{M} \mathrm{NaCl}$ with gentle stirring, rinsed with doubly distilled water and dried with $\mathrm{N}_{2}$, followed by a potentiostatic-step measurement.

The potentiostatic-step measurements were performed with

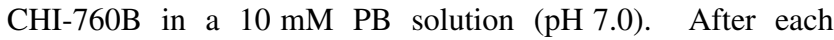
immunoassay, the film of $\mathrm{CuS}$ was regenerated by rinsing in a $0.1 \mathrm{M}$ glycine- $\mathrm{HCl}$ buffer ( $\mathrm{pH} 2.5$ ), and then washed with doubly distilled water. The regenerated $\mathrm{CuS}$ film could accomplish up to seven repetitive assays without any significant loss of the detection sensitivity.

\section{Results and Discussion}

\section{Capacitance evaluation}

There were two different ways to determine capacitance, namely an impedance measurement ${ }^{31-33}$ and a potentiostatic-step measurement. ${ }^{12}$ However, it took a lightly long time to acquire a full impedance spectra within a broad range of frequencies. The potentiostatic-step measurement was faster and more convenient and was used in the present work.

Measuring with a potentiostatic-step, it is necessary to adopt a relatively low electrolyte concentration. ${ }^{22}$ The current decay depends on the time constant $\left(\tau=C_{\mathrm{tot}} R_{\mathrm{s}}\right)$. The higher is the constant, the more slowly does the current decay. Since a low solution resistance is obtained at high electrolyte concentrations, the value of $\tau$ should be a low value. This means that only a few current values can be sampled before the current has decayed to zero.

The capacitance measurement with potentiostatic-steps was based on a theoretical assumption that the electrochemical system followed a simplified RC circuit. ${ }^{22}$ For such a theoretical mode, the potential was stepped from 50 to $0 \mathrm{mV}$ (vs. SCE), which caused current attenuation. The current decay evoked by a potential step agrees with the following equation:

$$
i(t)=u / R_{\mathrm{s}} \exp \left(-t / R_{\mathrm{s}} C_{\mathrm{tot}}\right),
$$

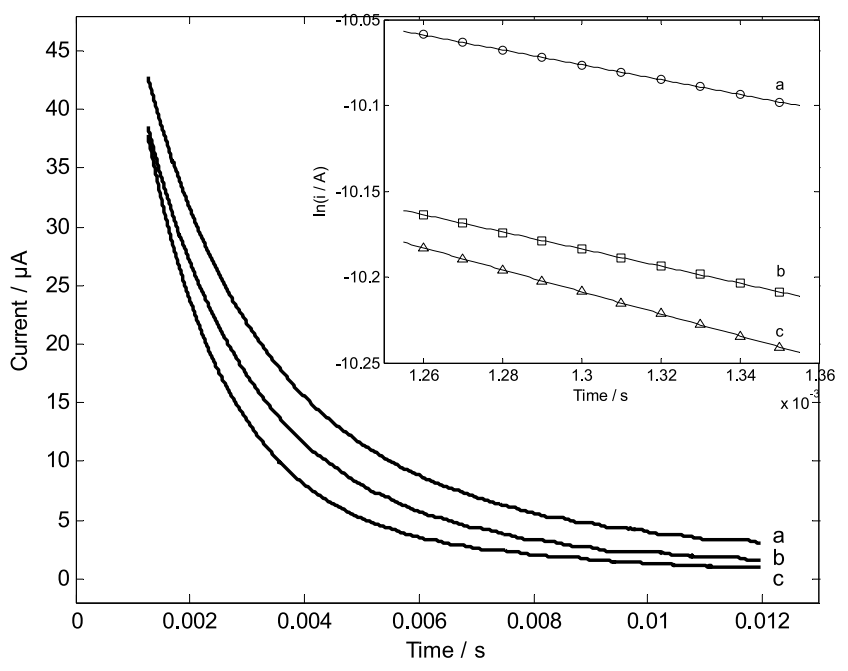

Fig. 2 Relation curves of current vs. time by applying a potentiostatic-step (from 50 to $0 \mathrm{mV} v s$. SCE) to a $\mathrm{CuS}$ film modified gold electrode (a), an antibody-immobilized electrode (b), and the resulting electrode after immunoreaction with human $\operatorname{IgA}$ (c) in a $10 \mathrm{mM}$ PB solution ( $\mathrm{pH}$ 7.0).

where $i(t)$ is the current in the circuit as a function of time, $u$ the potential step applied, $R_{\mathrm{s}}$ the dynamic resistance of the recognition layer, $C_{\text {tot }}$ the total capacitance measure at the working electrode/solution interface, and $t$ the time elapsed after the potentiostatic-step being applied. By taking the logarithm of Eq. (1), a linear relationship between $\ln (i)$ and $t$ can be obtained, as follows:

$$
\ln (i)=\ln (u)-\ln \left(R_{\mathrm{s}}\right)-t / R_{\mathrm{s}} C_{\mathrm{tot}}
$$

Then, $C_{\mathrm{tot}}$ and $R_{\mathrm{s}}$ can be easily calculated from the slope and intercept of the linear curve.

The sol-gel CuS film is insulated and extremely thin, which meets the demand of a capacitance measurement with the potentiostatic-step. Figure 2 shows the zoomed $i-t$ curve for a $\mathrm{CuS}$ film modified electrode (curve a), an antibody-immobilized electrode (curve b), and the resulting electrode after immunoreaction with an antigen (curve c). Only a few initial readings of the curves were linear, so the first ten current values were usually collected and used for the calculation, according to Eq. (2), which are shown in an insert plot of Fig. 2. Also, a correlation coefficient better than 0.99 was usually obtained.

\section{Electrochemical characterization of the immunosensor}

Cyclic voltammetry $(\mathrm{CV})$ of a fairly reversible redox couple in a $5.0 \mathrm{mM}\left[\mathrm{Fe}(\mathrm{CN})_{6}\right]^{3-14-}(0.1 \mathrm{M} \mathrm{KCl})$ of PB solution $(\mathrm{pH} 7.0)$ was monitored at a scanning rate of $100 \mathrm{mV} / \mathrm{s}$ in a sweeping range from -0.2 to $0.6 \mathrm{~V}$ to show the changes of the insulated property of the electrode with various layers of the $\mathrm{CuS}$ film. The obtained detailed results are shown in Fig. 3. As can be distinctly seen, a cyclic voltammogram for the bare gold electrode was comparatively reversible. However, when $\mathrm{S}^{2-}$ ions were chemisorbed on the resulting gold electrode, leading to the formation of a $\mathrm{CuS}$ bilayer, the insulating property of the electrode increased significantly, which was approved by a distinct decrease in the peak current of the redox probe. While the bilayers increased gradually, the assembly of the $\mathrm{CuS}$ bilayer became even-more compact and uniform on the surface of the electrode, indicating that the free transfer of electrons to the 


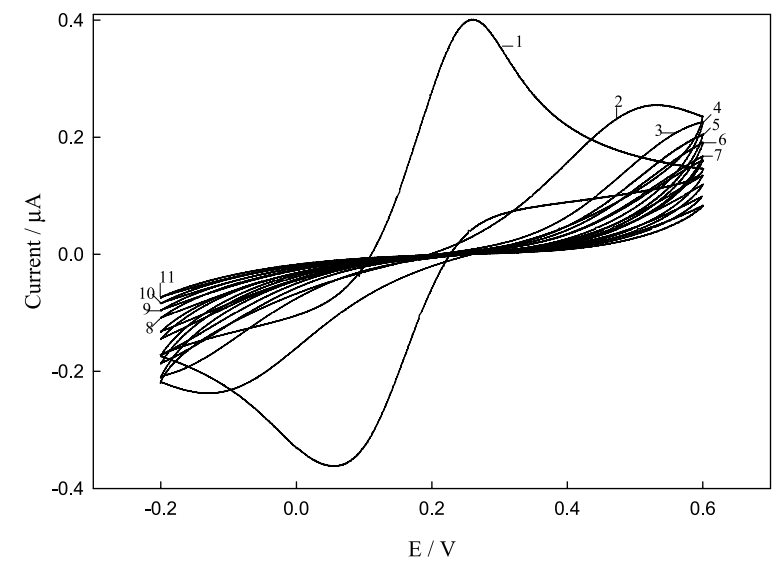

Fig. $3 \mathrm{CV}$ recorded in a $5.0 \mathrm{mM}\left[\mathrm{Fe}(\mathrm{CN})_{6}\right]^{3-/ 4-}(0.1 \mathrm{M} \mathrm{KCl})$ of $10 \mathrm{mM}$ PB solution ( $\mathrm{pH}$ 7.0) for a bare gold electrode (1) and a second $\mathrm{CuS}$ bilayer modified gold electrode to the eleventh $\mathrm{CuS}$ bilayer modified gold electrode (2 to 11 ). The scan rate was $100 \mathrm{mV} / \mathrm{s}$. The voltage range was $-0.2-0.6 \mathrm{~V}$.

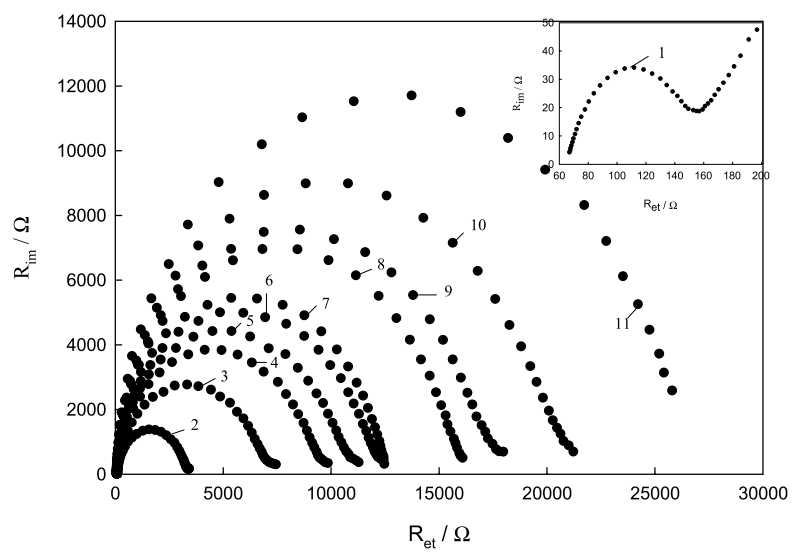

Fig. 4 Nyquist diagram of electrochemical impedance spectra of a bare gold electrode (1) and a second $\mathrm{CuS}$ bilayer modified gold electrode to the eleventh CuS bilayer modified gold electrode (2 to 11) in the frequency range from $0.1 \mathrm{~Hz}$ to $100 \mathrm{kHz}$. Amplitude of sinusoidal potential, $\pm 5 \mathrm{mV}$; fixed potential, $250 \mathrm{mV}$ ( $v s$. SCE); electrolyte, $5.0 \mathrm{mM}\left[\mathrm{Fe}(\mathrm{CN})_{6}\right]^{3-14}$ (1:1) in $10 \mathrm{mM}$ PB solution, $\mathrm{pH}$ 7.0.

conductive electrode surface did not go smoothly, and so the peak current of a redox probe was reduced stepwise. As illustrated in Fig. 3, 10 bilayers of $\mathrm{CuS}$ induced a basal insulation of the gold electrode, so its sol-gel film was adopted in this study. The impedance behavior of 10 bilayers of sol-gel film of CuS, shown in Fig. 4, also reflects this tendency. Therefore, the ten-bilayers of a $\mathrm{CuS}$ modified electrode with a good insulating property could be obtained and used to fabricate the capacitive immunosensor.

When increasing the concentration of $\mathrm{Cu}(\mathrm{OAc})_{2}(20,50 \mathrm{mM})$, but keeping the concentration of $\mathrm{Na}_{2} \mathrm{~S}$ unchanged, a strange phenomenon was found in preparing the $\mathrm{CuS}$ film, in that the electrode remained conductive even if 15 bilayers of $\mathrm{CuS}$ were assembled on its surface, indicating that a higher concentration of $\mathrm{Cu}(\mathrm{OAc})_{2}$ did not induce the formation of a compact and uniform bilayer of $\mathrm{CuS}$.

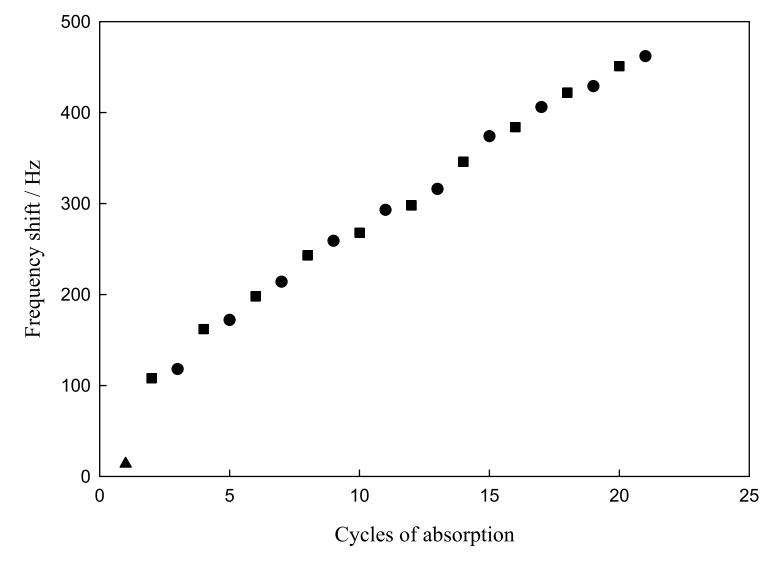

Fig. 5 Resonance frequency changes of QCM with molecular and ionic adsorption: cysteine $(\boldsymbol{\Delta}), \mathrm{Cu}^{2+}(\boldsymbol{\square}), \mathrm{S}^{2-}(\mathbf{O})$.

Film thickness with a microgravimetric evaluation

It is very important to know the thickness of the fabricated $\mathrm{CuS}$ ultrathin film. A quartz crystal microbalance (QCM) measurement has been used to monitor the preparation process of a film of a $\mathrm{CuS}$ layer-by-layer. Figure 5 shows that the frequency shift of the QCM increased when the CuS bilayers were stepwise assembled on the gold surface of the crystal by alternative dipping in $\mathrm{Na}_{2} \mathrm{~S}$ and $\mathrm{Cu}(\mathrm{OAc})_{2}$ solutions. The average change of the total frequency with $464 \mathrm{~Hz}(\mathrm{SD}=$ $\pm 13 \mathrm{~Hz}, n=5$ ) was obtained after $10 \mathrm{CuS}$ bilayers were adsorbed on the crystal. Because the copper ions could form a firm chelate, a five-membered heterocyclic compound, with $-\mathrm{NH}_{2}$ and $-\mathrm{COOH}$ groups of cysteine initially, the frequency decrease with the first adsorption of $\mathrm{Cu}^{2+}$ ions was almost three-times larger than that of other cycles of adsorption of $\mathrm{Cu}^{2+}$ ions. For one $\mathrm{CuS}$ bilayer assembled, the average frequency decrease due to the later 9-times adsorption of $\mathrm{S}^{2-}$ and $\mathrm{Cu}^{2+}$ ions could be calculated to be $17 \pm 2 \mathrm{~Hz}$ and $28 \pm 3 \mathrm{~Hz}(n=9)$, respectively. The thickness of ultrathin $\mathrm{CuS}$ film could be obtained by QCM measurements, that the relationship between the thickness of the deposited film $(d)$ and the frequency shifts $(\nabla f)$ could be derived from the Sauerbrey equation, ${ }^{34}$ which can be described by

$$
d=4.43 \times 10^{5} \frac{\nabla f}{\rho_{\mathrm{c}} f^{2}},
$$

where $d$ is the thickness of $\mathrm{CuS}$ film $(\mathrm{cm}), \nabla f$ the frequency shifts $(\mathrm{Hz}), \rho_{\mathrm{c}}$ the density of deposited film, and $f$ the primary frequency of the crystal $(\mathrm{Hz})$. Herein, the density of $\mathrm{CuS}$ is $4.6 \mathrm{~g} \mathrm{~cm}^{-3}$, the primary frequency is $9.0 \mathrm{MHz}$, and the frequency shift was measured as $464 \pm 13 \mathrm{~Hz}(n=5)$, so the thickness of a CuS ultrathin film of 10 bilayers was calculated to be $5.8 \pm 0.2 \mathrm{~nm}(n=5)$. Also, each bilayer of $\mathrm{CuS}$ could be evaluated to be $0.56 \pm 0.04 \mathrm{~nm}(n=9)$. Thereafter, the thickness of the film of the $\mathrm{CuS}$ bilayer could be easily controlled to meet the demand of the capacitive immunosensor by the experiment.

\section{Effect of the $\mathrm{pH}$ on capacitance immunosensors}

Since the medium $\mathrm{pH}$ had a commonly effect on the configurations and electrostatic states of proteins, the $\mathrm{pH}$ value should play a vital role in the immobilization of an antibody and the interaction of an antibody-antigen. The $\mathrm{pH}$ dependence of an adsorbing antibody on the surface of a $\mathrm{CuS}$ film-modified electrode was tested over a $\mathrm{pH}$ range from 5.0 to 9.0 in the 


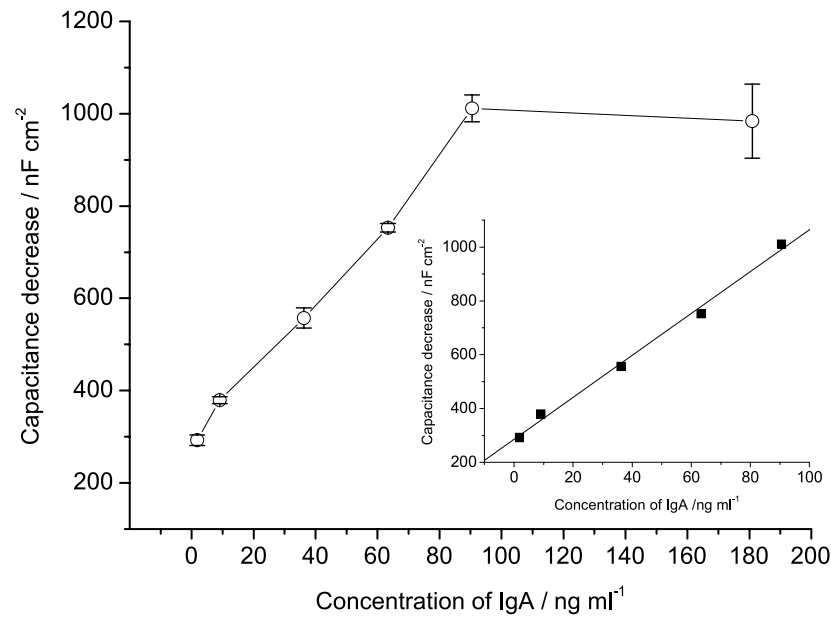

Fig. 6 Capacitance change $v s$. the concentration of human IgA for a CuS film modified IgA immunosensor. Insert: Linear relationship between the capacitance change and the concentration of human IgA. The measurements were carried out in a $10 \mathrm{mM}$ PB solution ( $\mathrm{pH} 7.0)$ with a potentiostatic-step. The standard deviations obtained by five repeated measurements are shown as error bars.

experiment (see Fig. S1, Supporting Information). For the adsorption of an antibody on the film of a CuS bilayer, the lower was the medium $\mathrm{pH}$, the larger was the capacitance of the immunosensor changed. However, for the adsorption of an antigen on the resulting sensing interface, the maximum change of the capacitance was observed at around $\mathrm{pH}$ 7.0. Therefore, taking the $\mathrm{pH}$ dependence of the denaturalization of a protein into account, an appropriate $\mathrm{pH}$ of 7.0 was chosen for the assay experiment.

\section{Detection of human IgA}

The interaction between human $\operatorname{IgA}$ (analyte) and goat anti-human IgA immobilized on the $\mathrm{CuS}$ film could be directly monitored by determining the capacitance with a potentiostatic-step. The capacitance changes resulting from the sensing of analyte human $\operatorname{IgA}$ with different concentrations are shown in Fig. 6. The capacitance change was observed to be linearly dependent upon the $\operatorname{IgA}$ concentration in the range of $1.81-90.5 \mathrm{ng} \mathrm{ml}^{-1}$ (Fig. 6 inset), and the calibration equation was obtained as $\Delta C\left(\mathrm{nF} \mathrm{cm}^{-2}\right)=285.3+7.797 c\left(\mathrm{ng} \mathrm{ml}^{-1}\right)$, with a correlation coefficient of $0.9973(n=5)$. The detection limit had a lowest value of $1.81 \mathrm{ng} / \mathrm{ml}$ that could be detected.

\section{Investigation on interference}

The interference from other proteins in real samples is a very important factor to be considered for a biosensor. Thus, the degree of nonspecific adsorption of other proteins for the anti-human $\mathrm{IgA}$ immobilized $\mathrm{CuS}$ film electrode was investigated. The modified electrode was incubated in a PB solution ( $\mathrm{pH} 7.0$ ) containing $1.0 \mathrm{mg} \mathrm{ml}^{-1} \mathrm{BSA}$, or $9.8 \mu \mathrm{g} \mathrm{ml}^{-1}$ complement III (C3), or $11.4 \mu \mathrm{g} \mathrm{m}^{-1} \mathrm{IgG}$ for $60 \mathrm{~min}$, and the capacitance response was measured with the potentiostatic-step method. The maximum change of the capacitance, $22.7 \mathrm{nF} \mathrm{cm}^{-2}$, generated from a nonspecific adsorption of BSA, had a negligible effect on the capacitance change caused by the interaction between anti-human $\operatorname{IgA}$ and the target antigen, human IgA, even though the concentration of BSA was much higher than that of IgA. This suggested that the observed capacitance change of the present immunosensor to human $\operatorname{IgA}$
Table 1 Recovery of human $\operatorname{Ig}$ A assay

\begin{tabular}{cccccc}
\hline No. & $\begin{array}{c}\text { Added } \\
\mathrm{IgA} / \\
\mathrm{ng} \mathrm{ml}^{-1}\end{array}$ & $\begin{array}{c}\Delta C / \\
\mathrm{nF} \mathrm{cm}^{-2}\end{array}$ & $\begin{array}{c}\text { Found } \\
\text { IgA/ } \\
\mathrm{ng} \mathrm{ml}^{-1}\end{array}$ & $\begin{array}{c}\text { Recovery, } \\
\%\end{array}$ & $\begin{array}{c}\text { RSD, } \\
\%\end{array}$ \\
\hline 1 & 3.62 & 313.2 & 3.58 & 98.9 & 8.7 \\
2 & 18.1 & 432.7 & 18.9 & 104.4 & 5.4 \\
3 & 54.3 & 720.4 & 55.8 & 102.8 & 7.2 \\
4 & 72.4 & 828.0 & 69.6 & 96.1 & 4.8 \\
\hline
\end{tabular}

antigen was due to its specific binding well on the electrode surface, and there were no obvious interferences from the nonspecific adsorption of other proteins.

\section{Reproducibility}

To examine the reproducibility of an immunosensor modified with the ultra-thin $\mathrm{CuS}$ film by the present fabrication procedure, various concentrations of human $\operatorname{IgA}$ in the linear detection range were determined with five different electrodes. The standard deviations for testing 36.2 and $54.3 \mathrm{ng} \mathrm{ml}^{-1}$ human IgA samples were \pm 22.0 and $\pm 51.9 \mathrm{nF} \mathrm{cm}^{-2}(n=5)$, respectively. The corresponding relative standard deviations were 3.9 and $7.2 \%$, respectively, indicating that the present immunosensor possessed nice reproducibility.

\section{Regeneration ability and recovery}

The reusability was also evaluated as an important feature of an immunosensor. Between immunoassays, regeneration of the used immunosensor was carried out in a stirred acidic medium of $0.1 \mathrm{M}$ glycine- $\mathrm{HCl}(\mathrm{pH} 2.5)$ for $15 \mathrm{~min}$. After seven cycles of use and regeneration for the same electrode, the percentage of capacitance change on the analyte human $\operatorname{IgA}$ decreased by $2.94 \%$. There was almost no obvious decrease in the capacitance response after the same electrode was used seven times, indicating that the anti-human $\operatorname{IgA}$ immobilized electrode also possessed nice stablity. Thus, the capacitive immunosensor could be reusable for at least seven times.

To examine the applicability and reliability of using the present immunosensor, the recovery experiment of four serum samples with the addition of different concentrations of human IgA from Xiang Ya Hospital (Changsha, China) was performed. All measurements were carried out five times; the results are listed in Table 1. The recovery of the $\mathrm{CuS}$ film-based immunosensor was obtained in the range of $96.1-104.4 \%$ with an average relative standard derivation (RSD) of $6.5 \%(n=4)$, indicating that the present immunosensor possessed promising applicability and reliability.

\section{Conclusions}

In the present work, a novel capacitance immunosensor based on ultrathin $\mathrm{CuS}$ films was successfully fabricated to directly determine human $\mathrm{IgA}$ antigen. The $\mathrm{CuS}$ films were electrically insulating, ultrathin $(5.8 \mathrm{~nm})$ and stable. CuS films with high permittivity increased the RC time constant of the immunosensors greatly, which satisfied the demand of potentiostatic-step measurements. With high sensitivity, selectivity, reproducibility and regeneration ability, the immunosensor can be well applied to the detection of human IgA in serum samples with a recovery of $96.1-104.4 \%$, indicating its promising applicability and reliability. 


\section{Acknowledgements}

This work has been supported by the projects of National High Technology Research and Development Program (863 Program) of China (2008AA100801), National Natural Science Foundation of China (20775010, 10772047, 20775023), Hunan Provincial Natural Science Foundation of China (09JJ3016), and Program for New Century Excellent Talents in University (NCET-10-0138), Ministry of Education of the People's Republic of China.

\section{Supporting Information}

The effect of the $\mathrm{pH}$ on the immunosensor based on a CuS film was shown in Fig S1. This material is available free of charge on the Web at http://www.jsac.or.jp/analsci/.

\section{References}

1. J. Wu, Z. F. Fu, F. Yan, and H. X. Ju, Trends Anal. Chem., 2007, 26, 679.

2. F. Ricci, G. Volpe, L. Micheli, and G. Palleschi, Anal. Chim. Acta, 2007, 605, 111.

3. E. R. Hirst, Y. J. Yuan, W. L. Xu, and J. E. Bronlund, Biosens. Bioelectron., 2008, 23, 1759.

4. S. J. Guo and S. J. Dong, Trends Anal. Chem., 2009, 28, 96.

5. C. Berggren, B. Bjarnason, and G. Johansson, Electroanalysis, 2001, 13, 173.

6. M. A. Potizzi, R. M. Pocinik, and G. J. Simpson, J. Am. Chem. Soc., 2005, 127, 1058.

7. A. Gebbert, M. Alvarez-Icaza, W. Stoecklein, and R. D. Schmid, Anal. Chem., 1992, 64, 997.

8. J. P. Gosling, "Principles and Practice of Immunoassay", ed. C. P. Price and D. J. Newman, 2nd ed., 1997, Stockton, New York, 349.

9. R. Edwards, "Principles and Practice of Immunoassay", ed. C. P. Price and D. J. Newman, 2nd ed., 1997, Stockton, New York, 325.

10. V. M. Mirsky, M. Mass, C. Krause, and O. S. Wolfbeis, Anal. Chem., 1998, 70, 3674

11. S. Zhang, J. J. Ding, Y. Liu, J. L. Kong, and O. Hofstetter, Anal. Chem., 2006, 78, 7592.

12. D. C. Jiang, J. Tang, B. H. Liu, P. Y. Yang, and J. L. Kong,
Anal. Chem., 2003, 75, 4578

13. C. Berggren and G. Johansson, Anal. Chem., 1997, 69, 3651.

14. O. Laczka, E. Baldrich, F. X. Muňoz, and F. J. del Campo, Anal. Chem., 2008, 80, 7239.

15. Z. S. Wu, J. S. Li, M. H. Luo, G. L. Shen, and R. Q. Yu, Anal. Chim. Acta, 2005, 528, 235.

16. G. Feriotto, M. Borgatti, C. Mischiati, N. Bianchi, and R. Gambari, J. Agric. Food Chem., 2002, 50, 955.

17. Z. Cao, F. C. Gong, M. Tu, M. X. Zeng, X. X. Huang, L. Zhang, S. Z. Tan, L. X. Sun, and N. Gu, Anal. Lett., 2009, 42, 2820.

18. S. D. Carrigan, G. Scott, and M. Tabrizian, Langmuir, 2005, 21, 5966.

19. C. S. Chiu and S. Gwo, Anal. Chem., 2008, 80, 3318.

20. S. Allen, X. Y. Chen, J. Davies, M. C. Davies, A. C. Dawkes, J. C. Edwards, C. J. Roberts, J. Sefton, S. J. B. Tendler, and P. M. Williams, Biochemistry, 1997, 36, 7457.

21. C. Berggren, B. Bjarnason, and G. Johansson, Biosens. Bioelectron., 1998, 13, 1061.

22. C. Berggren and G. Johansson, Anal. Chem., 1998, 69, 3651.

23. D. C. Jiang, J. Tang, B. H. Liu, P. Y. Yang, X. R. Shen, and J. L. Kong, Biosens. Bioelectron., 2003, 18, 1183.

24. J. Wang, J. A. Profitt, M. J. Pugia, and I. I. Suni, Anal. Chem., 2006, 78, 1769.

25. M. D. Porter, T. B. Bright, D. L. Allara, and C. E. D. Chidsey, J. Am. Chem. Soc., 1987, 109, 3559.

26. E. B. Troughton, C. D. Bain, G. M. Whitesides, R. G. Nuzzo, D. L. Allara, and M. D. Porter, Langmuir, 1988, 4, 365.

27. R. G. Nuzzo and D. L. Allara, J. Am. Chem. Soc., 1983, $105,4481$.

28. S. Krämer, R. R. Fuierer, and C. B. Gorman, Chem. Rev., 2003, 103, 4367

29. A. C. Liu, D. C. Chen, C. C. Lin, H. H. Chou, and C. H. Chen, Anal. Chem., 1999, 71, 1549.

30. Y. M. Yang, H. F. Ji, and T. Thundat, J. Am. Chem. Soc., 2003, 125,1124

31. Z. S. Wu, J. S. Li, T. Deng, M. H. Luo, G. L. Shen, and R. Q. Yu, Anal. Biochem., 2005, 337, 308.

32. E. Katz and I. Willner, Electroanalysis, 2003, 15, 913.

33. E. Katz, L. Alfonta, and I. Willner, Sens. Actuators, B, 2001, 76, 134

34. G. Sauerbrey, Z. Phys., 1959, 155, 206. 